\title{
HIDROLISADO PROTÉICO DE PESCADO OBTIDO POR VIAS QUÍMICA E ENZIMÁTICA A PARTIR DE CORVINA (Micropogonias furnieri)
}

\author{
Vilásia Guimarães Martins, Jorge Alberto Vieira Costa e Carlos Prentice-Hernández* \\ Escola de Química e Alimentos, Universidade Federal do Rio Grande, CP 474, 96201-900 Rio Grande - RS, Brasil
}

Recebido em 30/11/07; aceito em 10/7/08; punlicado na web em 27/11/08

\begin{abstract}
FISH PROTEIN HYDROLYZED OBTAINED BY CHEMICAL AND ENZYMATIC PROCESSES FROM CORVINA (Micropogonias furnieri). The fish proteins has the advantage of a high sensibility to the hydrolysis and also a balanced composition in aminoacids. The production of protein hydrolyzed from by-products of fish process industry has been receiving more attention on the last years. The aim of this work was to evaluate the production of protein hydrolyzed from Micropogonias furnieri through chemical and enzymatic methods, verifying some functional properties. The results showed that the production of the hydrolyzed improved some functional properties of the proteins found in the filet and in the waste, what is desirable for a subsequent application.
\end{abstract}

Keywords: fish; protein hydrolyzed; functional properties.

\section{INTRODUÇÃO}

De acordo com a Organização de Agricultura e Alimentos (FAO) sobre estatísticas de descarte e captura, estima-se que anualmente uma média de 7,3 milhões de toneladas de pescado são descartadas. ${ }^{1}$ A captura de pescado tem diminuído nos últimos anos, devido à pesca mais seletiva e à estrita regulamentação, mas ainda existem muitas oportunidades de reduzir as perdas durante o processamento do pescado. ${ }^{2}$

As proteínas musculares do pescado apresentam a vantagem de possuírem elevado valor biológico, decorrente da sensibilidade à hidrólise e de composição balanceada em aminoácidos, particularmente daqueles que costumam ser os limitantes em proteínas de origem vegetal, como a metionina e a cisteína. Outra vantagem relacionada com o uso do pescado é o fato de que certas espécies não são apropriadas para a comercialização, geralmente, por não possuírem rendimento satisfatório com relação à filetagem, devido à estrutura corporal e por apresentarem baixo valor comercial. ${ }^{3}$

Os hidrolisados podem ser definidos como proteínas que são clivadas química ou enzimaticamente em peptídeos de vários tamanhos. ${ }^{4}$ Hidrolisados protéicos são produzidos para serem utilizados em ampla variedade de produtos alimentícios, incluindo substitutos de leite, suplementos protéicos, realçadores de sabor e estabilizadores em bebidas, dentre outros.

Para realizar a hidrólise, métodos químicos e biológicos são amplamente utilizados; a hidrólise química é mais comumente utilizada na prática industrial, porém os processos biológicos que utilizam adição de enzimas são mais promissores quando se deseja produtos com alta funcionalidade e valor nutritivo. Existem muitas técnicas potenciais para a extração da proteína a partir de tecido animal. Estas incluem a utilização de água e solventes orgânicos, processos convencionais de cozimento, aplicação de altas pressões, secagem e extração a quente de óleo. ${ }^{5}$

Em geral, a hidrólise é um processo eficiente para a solubilização das proteínas do pescado. A produção de materiais solúveis que constituem o produto final da hidrólise depende de diversos fatores, tais como, reagentes químicos, tipo de enzima, substrato, $\mathrm{pH}$, temperatura, tempo de incubação e concentração da enzima. ${ }^{6}$ Proteases

*e-mail: dqmprent @furg.br como Alcalase e Flavourzyme, produzidas pela Novozymes, têm sido relatadas como eficientes para hidrolisar proteínas de pescado., ${ }^{2,7}$

Este trabalho teve por objetivo estudar a produção de hidrolisados protéicos a partir da corvina (Micropogonias furnieri) através de métodos químicos e enzimáticos, verificando as propriedades funcionais resultantes.

\section{PARTE EXPERIMENTAL}

\section{Matéria-prima}

As matérias-primas utilizadas foram filé e resíduo do processamento da corvina (Micropogonias furnieri) sendo esta espécie oriunda das indústrias processadoras de pescado da cidade de Rio Grande, estado do Rio Grande do Sul, Brasil. O pescado foi transportado rapidamente em recipientes com gelo (proporção de 1:1, pescado:gelo) para o Laboratório de Tecnologia de Alimentos da FURG (Universidade Federal do Rio Grande), onde foi realizada a obtenção dos hidrolisados protéicos. Inicialmente, o pescado foi lavado e filetado, e depois separados o filé do resíduo, estes foram lavados com água clorada $5 \mathrm{ppm}$, sendo o filé triturado em cutter e o resíduo em moedor com parafuso sem fim. Posteriormente, estes foram congelados a $-18^{\circ} \mathrm{C}$ e reservados até sua utilização.

\section{Enzimas}

Foram utilizadas duas enzimas, Alcalase 2.4 L, endopeptidase bacteriana produzida a partir do Bacillus lichenformis, e Flavourzyme, complexo de protease/peptidase produzido por fermentação submersa de uma linhagem selecionada do fungo Aspergillus oryzae, não modificado geneticamente, e utilizadas para hidrólise de proteínas sob condições neutras ou levemente ácidas. As condições ótimas relatadas para Flavourzyme 500 L são pH 5,0 a 7,0, com temperatura ótima em torno de $50^{\circ} \mathrm{C}$. A Flavourzyme tem atividade de $500 \mathrm{LAPU} \mathrm{g}^{-1}$. Uma LAPU é referente à unidade de leucina aminopeptidase, que é a quantidade de enzima que hidrolisa $1 \mu \mathrm{mol}$ de leucina- $\rho$-nitroanilida por min. As enzimas utilizadas foram produzidas pela empresa Novozymes, de Araucária, estado do Paraná. A atividade enzimática de cada uma das enzimas foi determinada pelo método descrito por Rebeca et al.. ${ }^{9}$ 


\section{Caracterização da matéria-prima e dos hidrolisados}

As matérias-primas e os hidrolisados foram caracterizados pelas análises de proteína, lipídios, umidade e cinzas. $\mathrm{O}$ pH foi medido em potenciômetro digital. Proteína, lipídios, umidade e cinzas foram analisadas de acordo com a metodologia recomendada pela AOAC. ${ }^{10}$

\section{Processos de obtenção do hidrolisado protéico}

Para obtenção dos hidrolisados protéicos foram realizados dois tipos de processo: químico e enzimático.

Foram realizados dois tipos de processo de extração química para a obtenção do hidrolisado protéico, sendo estes por solubilização ácida e alcalina, e posterior precipitação das proteínas, onde a amostra foi homogeneizada com água destilada na proporção de 1:5. A hidrólise foi realizada em reator de vidro encamisado, associado a um banho termostatizado e acoplado a um agitador. Como agente alcalinizante foi utilizado o $\mathrm{NaOH} 1 \mathrm{M}$ e como agente acidificante, $\mathrm{HCl}$ $1 \mathrm{~N}$. O processo alcalino foi de $20 \mathrm{~min}$ a $20^{\circ} \mathrm{C}$ e pH 12 e o processo ácido foi de $20 \mathrm{~min}$ a $30^{\circ} \mathrm{C}$ e pH 2,5. Após a extração, o hidrolisado foi centrifugado a 7500 x g por $15 \mathrm{~min}$. Nesta centrifugação, a amostra ficou separada em três fases, onde a fase superior (lipídios neutros) e a fase inferior (fração insolúvel) foram descartadas, e a fase intermediária (proteínas solúveis) foi submetida à precipitação ácida ou alcalina até atingir o ponto isoelétrico das proteínas $(\mathrm{pH}=$ $5,0)$, onde foi utilizado como agente acidificante o $\mathrm{HCl} 1 \mathrm{~N}$ e como alcalinizante o $\mathrm{NaOH} 1 \mathrm{M}$, com tempo de exposição de 20 min a 30 ${ }^{\circ} \mathrm{C}$ sob agitação. Após, foi realizada nova centrifugação a $7500 \mathrm{x} \mathrm{g}$ por $15 \mathrm{~min}$, onde foi descartado o sobrenadante e o precipitado foi considerado como isolado protéico, armazenado e reservado a -18 ${ }^{\circ} \mathrm{C}$ até ser liofilizado.

Os parâmetros do processo de hidrólise enzimática utilizados foram os melhores resultados obtidos por D'Avila, ${ }^{11}$ onde a hidrólise foi realizada no mesmo reator de vidro encamisado das extrações químicas, sendo que para Alcalase os parâmetros utilizados foram: concentração $0,5 \%$ de enzima substrato ${ }^{-1}, 60^{\circ} \mathrm{C}, \mathrm{pH} 8,0$ por $60 \mathrm{~min}$; e para a Flavourzyme foram: concentração $2 \%$ de enzima substrato ${ }^{-1}, 50$ ${ }^{\circ} \mathrm{C}, \mathrm{pH}$ 7,0 por $120 \mathrm{~min}$. Após a hidrólise, a amostra foi centrifugada a $7500 \mathrm{x}$ g por $15 \mathrm{~min}$. O sobrenadante foi descartado e o precipitado foi considerado como hidrolisado protéico. Este foi reservado a $-18^{\circ} \mathrm{C}$ até liofilização.

\section{Grau de hidrólise}

Atendendo a especificações dos fabricantes, o grau de hidrólise foi medido nos tempos $0,15,30,45$ e 60 min na hidrólise com Alcalase e nos tempos 0, 30, 60, 90 e 120 min na hidrólise com Flavourzyme. $\mathrm{O}$ grau de hidrólise foi calculado segundo a quantidade de proteína solúvel, conforme método descrito por Pezoa e Mellado. ${ }^{12}$

\section{Propriedades funcionais}

A determinação da capacidade de retenção de água foi realizada segundo Regenstein et al..$^{13}$ com modificações, sendo feita uma solução protéica $1 \%$ para cada um dos pHs testados (3, 5, 7, 9 e 11); após agitação a solução foi centrifugada a 3000 x g por $25 \mathrm{~min}$, e no sobrenadante foi realizada a determinação de proteína pelo método de Lowry et al.,${ }^{14}$ para que fosse possível descontar a quantidade de proteína solubilizada. O cálculo foi realizado dividindo-se a quantidade de líquido retido pela quantidade de proteína presente na amostra. A capacidade de retenção de óleo foi analisada segundo método descrito por Fonkwe e Singh, ${ }^{15}$ onde $0,5 \mathrm{~g}$ de proteína foi homogeneizada por 10 min com $10 \mathrm{~mL}$ de óleo de soja e, a seguir, a mistura foi centri- fugada a 9000 x g por 15 min. O cálculo foi realizado dividindo-se a quantidade de óleo retido pela quantidade de proteína existente na amostra. A solubilidade foi determinada segundo Morr et al. ${ }^{16} \mathrm{com}$ modificações, sendo utilizado $0,5 \mathrm{~g}$ de proteína adicionado de $2 \mathrm{~mL}$ de $\mathrm{NaCl}$ 0,1 M e $38 \mathrm{~mL}$ do tampão correspondente ( $\mathrm{pH}$ 3, 5, 7, 9 e 11). Posteriormente, o material foi agitado, o volume completado a $50 \mathrm{~mL}$ e centrifugado a $9000 \mathrm{x}$ g por $35 \mathrm{~min}$. As amostras foram filtradas e a quantidade de proteína solubilizada foi determinada pelo método de Lowry et al.. ${ }^{14} \mathrm{O}$ cálculo da solubilidade foi realizado a partir da Equação 1

$\%$ Solubilidade $=\frac{A * 50}{W * S / 100}$

onde, A é a concentração de proteína em $\mathrm{mg} \mathrm{mL}^{-1}$; $\mathrm{W}$ é o peso da amostra em mg; $\mathrm{S}$ é a quantidade de proteína na amostra original em porcentagem.

\section{Liofilização}

As matérias-primas e os hidrolisados foram liofilizados em equipamento da marca Edwards com capacidade para 1,5 L, sendo as amostras mantidas à temperatura de $-70{ }^{\circ} \mathrm{C}$ por $15 \mathrm{~h}$, antes de serem liofilizadas por $24 \mathrm{~h}$.

\section{RESULTADOS E DISCUSSÃO}

Um dos problemas usualmente encontrados na hidrólise protéica com vísceras de pescado é a falta de reprodutibilidade, causada principalmente pela presença de proteases endógenas, as quais podem agir sobre o processo de hidrólise. Porém, isto vai depender do uso final destinado a esses hidrolisados, pois qualquer processo posteriormente utilizado desnaturaria as proteínas, o que não é desejado. Essa desnaturação das proteínas foi relatada por Guerard et al. ${ }^{17}$ que, interessados em inativar as enzimas endógenas do estômago do atum, principalmente a pepsina, realizaram uma cocção antes do tratamento enzimático. Conseqüentemente, a desnaturação das proteínas foi uma explicação razoável para a perda da habilidade da Alcalase para uma hidrólise eficiente das proteínas desnaturadas por causa da baixa flexibilidade das mesmas.

Mohr ${ }^{18}$ observou que, durante o aquecimento à temperatura da hidrólise, as proteínas da fração sarcoplásmica podem desnaturar e precipitar. Isto é mais evidente quando o material in natura é aquecido antes para inativar as enzimas endógenas do pescado. Estas proteínas desnaturadas são aparentemente altamente resistentes à quebra enzimática, conseqüentemente, só uma parte minoritária das proteínas desnaturadas será solubilizada durante a subseqüente hidrólise enzimática.

\section{Composição centesimal}

O resíduo liofilizado apresentou $64,26 \%$ de proteínas, $21,09 \%$ de lipídios e $8,07 \%$ de cinzas. Nos isolados, obtidos por extração química ácida e alcalina foi observado aumento na quantidade de proteína, sendo esta de 86,94 e 72,34\%, respectivamente. Nos hidrolisados enzimáticos foram obtidos valores menores, $50,15 \%$ para o hidrolisado com Flavourzyme e 47,09\% para o hidrolisado com Alcalase. Esses valores baixos estão relacionados com a alta quantidade de lipídios encontrados nesses hidrolisados (30,43 e 23,37\%, respectivamente), enquanto que nos processos ácido e alcalino os valores de lipídios encontrados foram de 3,47 e 6,58\%, respectivamente. Essa diferença acontece devido às diferentes etapas de processo do método químico para o enzimático, pois na extração química a maioria dos lipídios 
foi extraída juntamente com a fração das proteínas insolúveis pela centrifugação, porém no método enzimático há uma precipitação simultânea das proteínas insolúveis e solúveis, devido à temperatura que foi realizada a hidrólise, interferindo nessa separação. Diminuindo o conteúdo de lipídios no hidrolisado protéico pode-se contribuir significantemente para a estabilidade da oxidação lipídica. Isto pode aumentar a estabilidade do produto. ${ }^{19-21} \mathrm{O}$ conteúdo de cinzas nos isolados ácido e alcalino foi menor que $1 \%$, enquanto nos hidrolisados enzimáticos esses valores foram de $12,98 \%$ para a Flavourzyme e $16,84 \%$ para a Alcalase. Segundo Marquez et al.,22 a elevada concentração de cinzas verificada nos hidrolisados de maria-luiza (Paralonchurus brasiliensis) e perna-de-moça (Cynoscion sp), de 10,7 a $18,7 \%$ é decorrente da formação de $\mathrm{NaCl}$ em razão do ajuste do $\mathrm{pH}$ durante a hidrólise enzimática das proteínas. Elevados teores de minerais também foram encontrados por Liceaga-Gesualdo e Lichan, ${ }^{23} \mathrm{em}$ hidrolisados protéicos de arenque $(21,7 \%)$ e por Diniz e Martin, ${ }^{19}$ em estudo realizado com cação (14\%).

O filé liofilizado apresentou 75,51\% de proteína, 7,09\% de lipídios e $3,81 \%$ de cinzas. Os valores de proteínas encontrados para os hidrolisados liofilizados foram 77,98\% para a extração ácida, $88,28 \%$ para o processo alcalino, $81,43 \%$ para a hidrólise com a Flavourzyme e 70,53\% para a Alcalase. O conteúdo de proteína do hidrolisado foi similar ao relatado em outras pesquisas, entre 70 e $90 \%{ }^{8,24,25}$ O conteúdo de cinzas ficou abaixo de $1 \%$ para os isolados químicos e $7,75 \%$ para o ensaio com a Flavourzyme e 13,64\% para a Alcalase. Esse aumento no conteúdo de cinzas já era esperado, pois durante a hidrólise enzimática ocorre a formação de sais devido à adição de bases. Liceaga e Li-chan ${ }^{23}$ observaram que o conteúdo de cinzas no hidrolisado de salmão realizado com Alcalase foi $21 \%$ maior que no material inicial. Isto foi consequiência da adição de álcali requerido para o controle do pH durante a hidrólise. O conteúdo de lipídios encontrado foi de 3,13\% para o processo ácido, 4,35\% para o alcalino, 9,05\% para a hidrólise com a Flavourzyme e 13,70\% com Alcalase. Utilizando a mistura de enzimas endo- e exopeptidase Flavourzyme ${ }^{\mathrm{TM}}$ para a produção de um hidrolisado protéico de pescado a partir de um concentrado solúvel de pescado, Nilsang et al. ${ }^{26}$ obtiveram um hidrolisado com $66,4 \%$ de proteína, 2,37\% de lipídios e 25,94\% de cinzas.

\section{Grau de hidrólise}

Na Figura 1 está representado o grau de hidrólise dos ensaios realizados com as enzimas Flavourzyme e Alcalase, nos substratos utilizados. Foi observado que a enzima Flavourzyme, embora com o dobro do tempo de hidrólise da Alcalase, alcançou um grau de hidrólise máximo em torno de $18 \%$, independentemente do substrato utilizado. Este resultado era esperado, pois a Flavourzyme é uma exo-enzima. A Alcalase obteve um grau de hidrólise de 56\% para o filé e $37 \%$ para o resíduo, após 60 min de hidrólise. Essa diferença entre o filé e o resíduo provavelmente foi devida às diferentes frações protéicas encontradas nos substratos. A Alcalase é uma endo-enzima, conseguindo, portanto, uma hidrólise mais efetiva em tempo menor, quando comparada com a Flavourzyme.

\section{Capacidade de retenção de água}

Os resultados obtidos para a capacidade de retenção de água do filé in natura e dos hidrolisados nos diferentes pHs estudados estão apresentados na Figura 2.

Todos os ensaios apresentaram o mínimo de capacidade de retenção de água a $\mathrm{pH}$ 5,0. Isto era esperado, pois o $\mathrm{pH}$ 5,0 é o mais próximo do ponto isoelétrico dessas proteínas, fazendo com que este provoque a menor solubilidade e por isto, maior precipitação das proteínas. Os hidrolisados enzimáticos obtiveram menor capacidade de retenção de

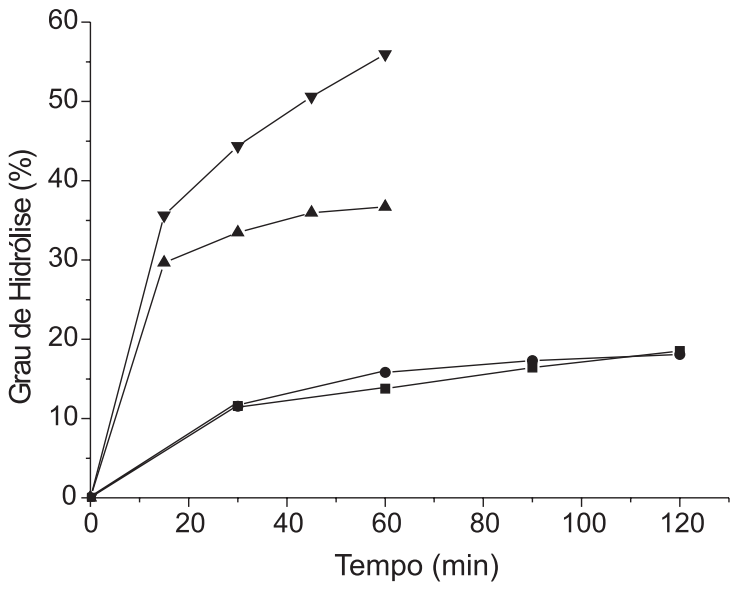

Figura 1. Grau de hidrólise enzimática do filé e do resíduo da corvina. Resíduo e Flavourzyme; • Filé e Flavourzyme; $\mathbf{\Delta}$ Resíduo e Alcalase; $\mathbf{\nabla}$ Filé e Alcalase

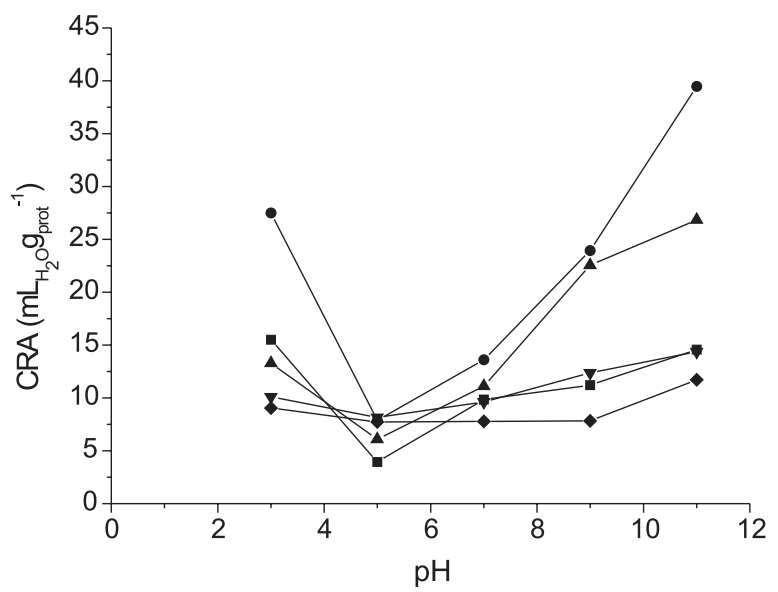

Figura 2. Capacidade de retenção de água do filé e dos hidrolisados em diversos pHs. - Filé • Extração Ácida $\Delta$ Extração Alcalina $\mathbf{\nabla}$ Hidrólise Flavourzyme $\bullet$ Hidrólise Alcalase

água, quando comparados com os hidrolisados químicos; provavelmente isso ocorreu devido à grande quantidade de peptídeos de baixo peso molecular gerados durante a hidrólise, que acaba prejudicando a absorção de água. Segundo Kristinsson, ${ }^{27}$ a hidrólise com Alcalase produz mais peptídeos com baixo peso molecular que com outras enzimas. Os menores resultados de capacidade de retenção de água foram encontrados no ensaio utilizando a Alcalase, o que está de acordo com Diniz e Martin ${ }^{19}$ que estudaram a hidrólise protéica utilizando tubarão como substrato, e observaram que o controle, representando o substrato protéico original de tubarão, obteve valores significativamente maiores de capacidade de retenção de água que as outras amostras (hidrolisado por Alcalase e por autólise), presumidamente devido às cadeias laterais hidrofílicas da proteína original. De acordo com Bernardi Don et al. ${ }^{28}$ a proteína apresenta-se na forma de rede, a qual é degradada pela hidrólise com conseqüente diminuição da capacidade de absorção de água. A extração química conseguiu aumentar a capacidade de retenção de água em praticamente todos os pHs, a extração ácida, no pH 11,0 aumentou de 14,56 $\mathrm{mL}_{\text {prot. }}{ }^{-1}$ no filé in natura para $39,47 \mathrm{~mL} \mathrm{~g}_{\text {prot. }}{ }^{-1}$. Já no processo alcalino foi obtido um acréscimo de $84 \%$ na CRA no $\mathrm{pH} 11,0$, que foi o $\mathrm{pH}$ onde se alcançou a maior capacidade de retenção de água; os pHs 5,0 e 7,0 foram os que obtiveram as menores CRAs para todos os ensaios.

Na Figura 3 estão apresentados os resultados de capacidade de retenção de água obtidos para os ensaios realizados com resíduo da corvina (Micropogonias furnieri). 


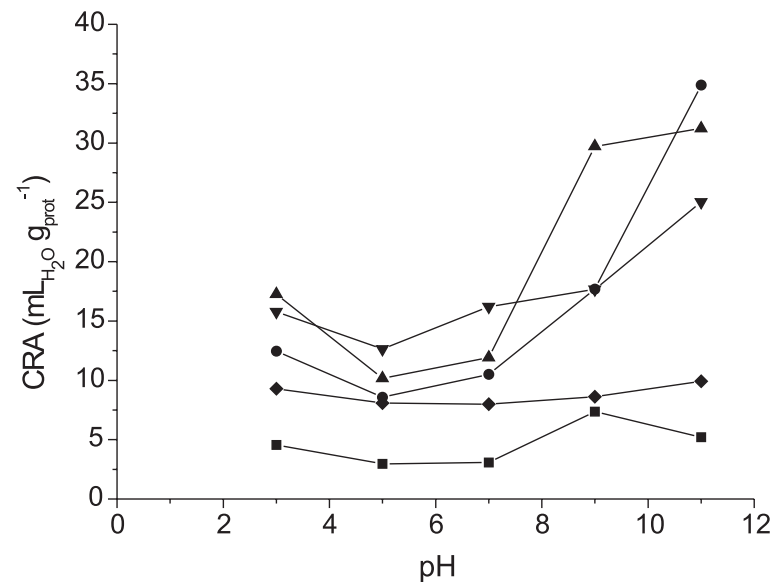

Figura 3. Capacidade de retenção de água do resíduo e dos hidrolisados em diversos pHs. - Resíduo • Extração Ácida $\Delta$ Extração Alcalina $\mathbf{\nabla}$ Hidrólise Flavourzyme $\bullet$ Hidrólise Alcalase

Os ensaios com resíduo apresentaram a mínima capacidade de retenção de água no $\mathrm{pH}$ 5,0, devido à precipitação das proteínas pela aproximação ao ponto isoelétrico. O resíduo original apresentou uma CRA muito baixa em todos os $\mathrm{pHs,} \mathrm{sendo} \mathrm{o} \mathrm{valor} \mathrm{máximo} \mathrm{de}$ 7,37 $\mathrm{mL} \mathrm{g}_{\text {prot. }}{ }^{-1}$ no $\mathrm{pH} 7,0$. Os hidrolisados enzimáticos apresentaram valores menores que os hidrolisados químicos, porém o hidrolisado enzimático com a Alcalase apresentou $9,92 \mathrm{~mL} \mathrm{~g}_{\text {prot. }}{ }^{-1}$, enquanto que $\mathrm{o}$ hidrolisado com a Flavourzyme apresentou CRA de 25,2 mL g ${ }_{\text {prot. }}{ }^{-1}$ no pH 11,0. Isto está de acordo com Diniz e Martin, ${ }^{19}$ que encontraram menores resultados de capacidade de retenção de água no ensaio que utilizou Alcalase no hidrolisado protéico a partir de resíduo de tubarão. O processo químico alcançou valores máximos no $\mathrm{pH}$ 11,0 de $34,89 \mathrm{~mL} \mathrm{~g}_{\text {prot. }}{ }^{-1}$ para a extração ácida e de $31,23 \mathrm{~mL} \mathrm{~g}_{\text {prot. }}{ }^{-1}$ para o processo alcalino. $\mathrm{O} \mathrm{pH}$ afeta a magnitude da carga da rede sobre as moléculas protéicas, a qual, em troca, altera as interações atrativas e repulsivas. As proteínas são capazes de ligar grande quantidade de água por causa da habilidade de formar ponte de hidrogênio entre moléculas de água e grupos polares de polipeptídeos. ${ }^{29}$

Não foi observada uma relação entre o grau de hidrólise e a capacidade de retenção de água para ambos os substratos e enzimas utilizadas.

\section{Capacidade de retenção de óleo}

Os resultados da capacidade de retenção de óleo para o filé e os hidrolisados são mostrados na Figura 4. Todos os hidrolisados

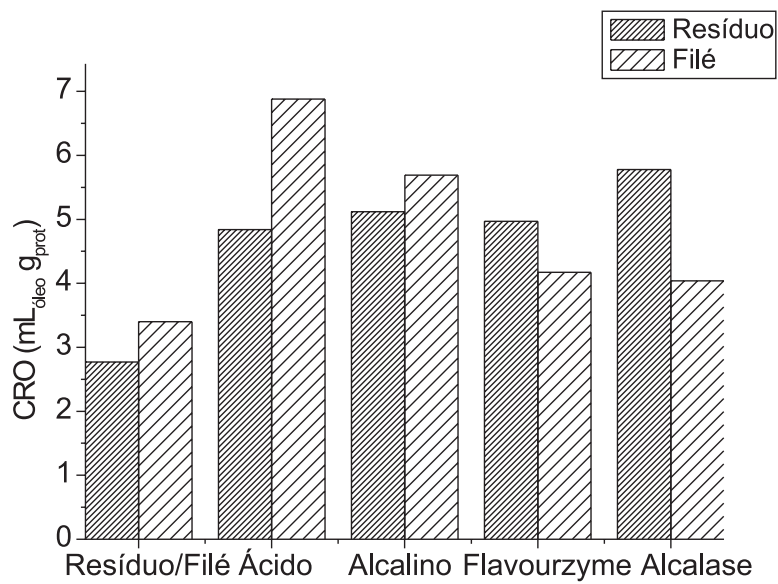

Figura 4. Capacidade de retenção de óleo no filé, nos resíduos e hidrolisados protéicos de corvina obtiveram valores superiores ao encontrado para o filé in natura. Os maiores resultados foram obtidos para os hidrolisados químicos, o processo ácido obteve um aumento de $102 \%$ e o alcalino, de $67 \%$, em relação ao filé original. Os processos enzimáticos obtiveram valores próximos, aumentando a absorção de óleo em torno de $20 \%$.

Os resultados da capacidade de retenção de óleo para o resíduo e os hidrolisados são apresentados na Figura 4. O resíduo original apresentou absorção de óleo de $2,77 \mathrm{~mL}_{\text {prot. }}{ }^{-1}$; todos os hidrolisados alcançaram valor superior ao do resíduo in natura. Os resultados dos hidrolisados foram próximos, sendo que o máximo alcançado foi com o uso da Alcalase $\left(5,78 \mathrm{~mL} \mathrm{~g}_{\text {prot. }}{ }^{-1}\right)$. Os resultados obtidos foram relativamente maiores que os encontrados na literatura. Estudo realizado por Slizyte et al..$^{30}$ com hidrólise realizada com resíduos de bacalhau mostrou que a habilidade das misturas de absorverem óleo foi constante, em torno de 2,3 $\mathrm{g}_{\text {oleo }} \mathrm{g}_{\text {prot }}{ }^{-1}$, para todas as amostras. A quantidade presente de lipídios nas amostras aparentemente não interferiu na absorção de óleo, pois os hidrolisados apresentaram resultados diferentes de lipídios e a capacidade de retenção de óleo foi praticamente a mesma para todos, com exceção do resíduo original. Porém alguns pesquisadores encontraram relação entre a quantidade de lipídios e a absorção de óleo; os hidrolisados enzimáticos de resíduos de bacalhau (com Flavourzyme e Neutrase) contendo a maior quantidade de lipídios obtiveram a maior absorção de óleo, enquanto que a mistura original apresentou a tendência oposta, onde a maior quantidade de lipídios obteve a menor capacidade de retenção de óleo. ${ }^{30}$

O grau de hidrólise não influenciou na absorção de óleo, mesmo a Alcalase tendo apresentado praticamente o dobro do grau de hidrólise da Flavourzyme para o resíduo, e três vezes mais para o filé; os resultados foram muito próximos e independentes do substrato utilizado. Em estudo realizado por Gbogouri et al ${ }^{31}$ com cabeças de salmão, mostrou que o hidrolisado com grau de hidrólise de 11,5\% apresentou melhor capacidade de retenção de óleo que os hidrolisados com maior grau de hidrólise e que o caseinato de sódio. A proteína de salmão não-hidrolisada obteve uma capacidade de retenção de óleo significativamente maior que o hidrolisado.

\section{Solubilidade}

Os resultados de solubilidade para o filé in natura e os hidrolisados são apresentados na Figura 5. A solubilidade foi mínima no $\mathrm{pH}$ 5,0 para todos os ensaios. Em pH 5,0, no ponto isolelétrico a carga da rede da proteína é minimizada e conseqüentemente se formam mais interações proteína-proteína e menos interações proteína-água, e por isso a solubilidade diminui. ${ }^{32,33}$

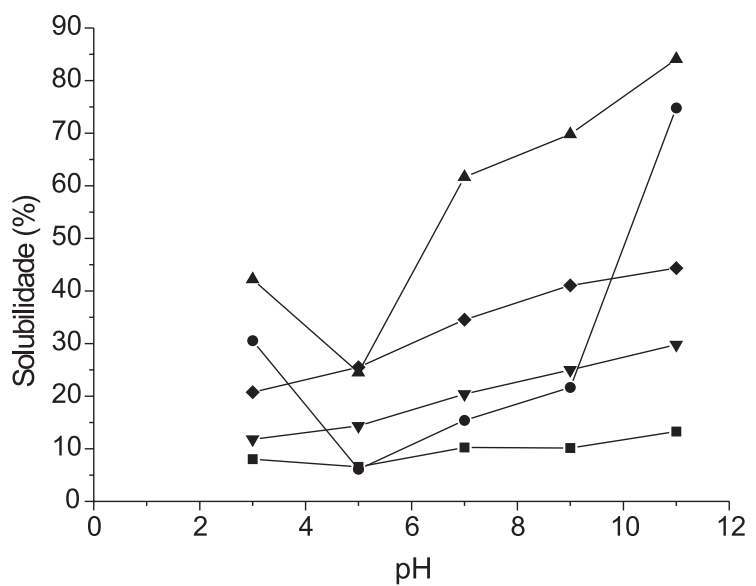

Figura 5. Solubilidade apresentada pelo filé e hidrolisados de corvina. - Resíduo • Extração Ácida $\boldsymbol{\Delta}$ Extração Alcalina $\mathbf{\nabla}$ Hidrólise Flavourzyme - Hidrólise Alcalase 
A maior solubilidade foi alcançada em $\mathrm{pH}$ extremos, sendo que no $\mathrm{pH}$ 11,0 foram obtidas as solubilidades máximas, concordando com Kristinsson e Rasco o ${ }^{8}$ H é muito importante na influência que exerce sobre a solubilidade, pois influencia na carga sobre os grupos das cadeias laterais ácidas e alcalinas, portanto, as proteínas e os hidrolisados protéicos geralmente apresentam baixa solubilidade no ponto isoelétrico e alta solubilidade, quando se trabalha em extremos de $\mathrm{pH}$.

Os extratos ácido e alcalino apresentaram os maiores resultados (74,81 e 84,09\%, respectivamente). A hidrólise enzimática alcançou valores de $29,82 \%$ para a Flavourzyme e $44,36 \%$ para a Alcalase; como a Alcalase apresentou grau de hidrólise maior, era esperado que obtivesse uma solubilidade maior que a Flavourzyme. O filé não hidrolisado foi o que apresentou a menor solubilidade $(13,27 \%) \mathrm{em}$ $\mathrm{pH}$ 11,0. A quebra enzimática das proteínas envolve uma mudança estrutural, a proteína é gradualmente clivada em unidades menores de peptídeos, havendo assim aumento na solubilidade maior que nas proteínas intactas. Segundo Gbogouri et al. ${ }^{31}$ o balanço das forças hidrofílicas e hidrofóbicas dos peptídeos é outro fator importante no aumento da solubilidade. Espera-se que peptídeos menores gerados a partir das proteínas miofibrilares apresentem mais resíduos polares, com a habilidade de formar pontes de hidrogênio com a água, o que aumenta a solubilidade. Linder et al $^{34} \mathrm{e}^{3}$ Kristinsson e Rasco trabalharam com hidrolisados de filé de salmão; estes foram mais solúveis do que a proteína nativa e indicaram solubilidades superiores a $75 \%$. O realce da solubilidade é decorrente dos tamanhos moleculares menores dos hidrolisados quando comparados com a proteína intacta.

Os resultados de solubilidade encontrados para resíduo e hidrolisados são apresentados na Figura 6. A menor solubilidade para todos os ensaios foi em pH 5,0, assim como aconteceu para os hidrolisados de filé. A solubilidade máxima encontrada foi em $\mathrm{pH}$ 11,0 para todas as amostras. Os hidrolisados químicos apresentaram maiores valores de solubilidade $(88,99 \%$ para o isolado ácido e $86,59 \%$ para o isolado alcalino). O resíduo original alcançou um valor máximo de $9,51 \%$ e os hidrolisados enzimáticos apresentaram $45,87 \%$ para a Flavourzyme e $57 \%$ para a Alcalase. Batista ${ }^{35}$ estudou a solubilidade da proteína dos hidrolisados de resíduo de pescado por extração alcalina e observou que a solubilidade aumentou tanto no lado ácido quanto alcalino, embora o aumento da solubilidade fosse mais pronunciado no lado alcalino.

O aumento na solubilidade dos hidrolisados é devido ao menor tamanho molecular comparado com a proteína intacta, e também à exposição de novos grupos aminos e carboxilas ionizáveis dos

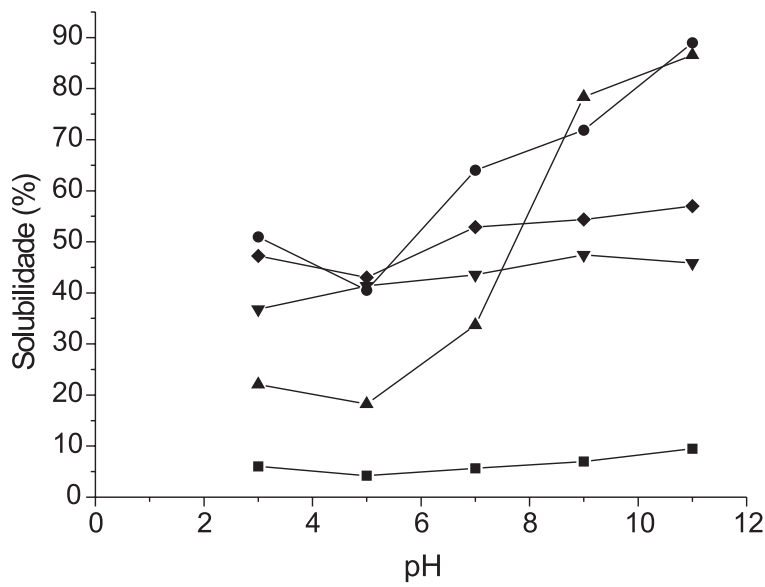

Figura 6. Solubilidade apresentada pelo resíduo e hidrolisados de corvina.

- Resíduo • Extração Ácida $\Delta$ Extração Alcalina $\mathbf{\nabla}$ Hidrólise Flavourzyme

- Hidrólise Alcalase aminoácidos, que aumentam a hidrofilicidade do hidrolisado. Tal comportamento é explicado pelo fato que são produzidos polipeptídeos menores e mais hidrofílicos durante a hidrólise; por isso, não há formação de agregados longos, a não ser no ponto isoelétrico. ${ }^{36}$

Os resultados das propriedades funcionais dos hidrolisados estudados mostraram que os mesmos poderiam ser utilizados para diversas aplicações na indústria de alimentos. A extração química apresentou resultados mais expressivos quando comparada com a hidrólise enzimática; além disso, os processos químicos são de fácil execução e de custo operacional menor.

As aplicações do hidrolisado podem ser aumentadas pela melhor descrição de todas as frações após a hidrólise, percebendo aplicações também para a fração insolúvel. Poucos trabalhos têm sido realizados sobre a avaliação da parte insolúvel após a hidrólise. O valor do processo de hidrólise poderia ser aumentado significantemente pela continuação da hidrólise e/ou encontrando uso e aplicação para as frações não hidrolisadas.

\section{CONCLUSÃO}

Os substratos utilizados mostraram-se adequados para a produção dos hidrolisados, porém os resultados realçaram que seria mais vantajoso utilizar o resíduo que o filé. Os hidrolisados provenientes do resíduo da corvina apresentaram resultados satisfatórios em todas as propriedades funcionais avaliadas; além disso, o resíduo de pescado, que geralmente é utilizado para produzir farinha ou ração animal, poderia ser utilizado para a elaboração de um produto com maior valor agregado.

\section{AGRADECIMENTOS}

Ao CNPq pelo financiamento do projeto e à CAPES pela bolsa.

\section{REFERÊNCIAS}

1. Kelleher, K.; FAO fisheries technical, paper 470, 2005.

2. Dumay, J.; Donnay-Moreno, C.; Barnathan, G.; Jaquen, P.; Berge, J. P.; Process Biochem. 2006, 41, 2332.

3. Bárzana, E.; Garibay-García, M.; Production of fish protein concentrates in Fisheries processing: biotechnological applications, Chapman\&Hall: London, 1994.

4. Skanderby, M.; Food Technol. Int. Eur. 1994, 10, 141.

5. Pigott, G. M.; Chemistry and Biochemistry of Marine Food Products, AVI Publishing Company: Westport, 1982.

6. Adler-Nissen, J.; Enzymic Hydrolysis of Food Proteins, Elsevier Applied Science Publishers: Copenhagen, 1986.

7. Normah, I.; Jamilah, B.; Saari, N.; Yaakob, B. C. M.; J. Muscle Foods 2005, 16, 102 .

8. Kristinsson, H. G.; Rasco, B.; J. Agric. Food Chem. 2000, 48, 666.

9. Rebeca, B. D.; Pena-Vera, M. T.; Diaz-Castaneda, M.; J. Food Sci. 1991, $56,309$.

10. AOAC; Official Methods of Analysis of International, $16^{\text {th }}$ ed., USA, 1995.

11. D’Avila, S.S.; Dissertação de Mestrado, Fundação Universidade Federal do Rio Grande, Brasil, 2006.

12. Pezoa, V. G.; Mellado, M. S.; Obtenção de um concentrado de proteínas de pescado para alimentos pelo método enzimático, FURG: Rio Grande, 1979.

13. Regenstein, J. M.; Jauregui, C A.; Baker, R.; J. Food Biochem. 1984, 8, 131.

14. Lowry, O. H.; Rosebrough, N. J.; Farr, A. L.; Randall, R. J.; J. Biopl. Chem. 1951, 193, 275.

15. Fonkwe, L. G.; Singh, R. K.; Process Biochem. 1996, 31, 616. 
16. Morr, V.; German, B.; Kinsella, J. E.; Regenstein, J. M.; Van Buren, J. P.; Killara, A.; Lewis, B. A.; Mangino, M. E.; J. Food Sci. 1985, 50, 1715.

17. Guerard, F.; Dufosse, L.; De La Broise, D.; Binet, A.; J. Mol. Catal. B: Enzym. 2001, 11, 1059.

18. Mohr, V.; Process Biochem. 1980, 15, 21.

19. Diniz, F. M.; Martin, A. M.; Lebensm.-Wiss. Technol. 1997, 30, 272.

20. Shahidi, F.; Han, X. Q.; Synowiccki, J.; Food Chem. 1995, 53, 293.

21. Synowiecki, J.; Al-Khateeb, N.; Food Chem. 2000, 68, 152.

22. Marquez, V. M. L.; Neves, R. A. M.; Mira, N. V. M.; Ciênc. Tecnol. Aliment. 2004, 24, 108.

23. Liceaga-Gesualdo, A. M.; Li-Chan, E. C. Y.; J. Food Sci. 1999, 64, 1004.

24. Benjakul, B.; Morrissey, M. T.; J. Agric. Food. Chem. 1997, 61, 138.

25. Imm, J. Y.; Lee, C. M.; J. Agric. Food Chem. 1999, 47, 2366.

26. Nilsang, S.; Lertsiti, S.; Suphantharika, M.; Assavanig, A.; J. Food Eng. 2005, 70, 578 .
27. Kristinsson, H. G.; Masters Thesis, University of Washington, USA, 1998.

28. Bernardi Don, L. S.; Pilosof, A. M. R.; Bartholomai, G. B.; J. Am. Oil Chem. Soc. 1991, 68, 105.

29. Jones, L. J.; Tung, M. A.; Can. Inst. Food Sci. Technol. J. 1983, 16, 62.

30. Slizyte, R.; Dauksas, E.; Falch, E.; Storro, I.; Rustad, T.; Process Biochem. 2005, 40, 2033.

31. Gbogouri, G. A.; Linder, M.; Fanni, J.; Parmentier, M.; J. Food Sci. 2004, 69, 622 .

32. Chobert, J. M.; Bertrand-Harb, C.; Nicolas, M. G.; J. Agric. Food Chem. 1988, 36, 886.

33. Adler-Nissen, J.; J. Agric. Food Chem. 1976, 24, 1093.

34. Linder, M.; Fanni, J.; Parmentier, M.; J. Food Sci. 1996, 61, 716.

35. Batista, I.; Eur. Food Res. Technol. 1999, 210, 89.

36. Cheftel, J. C.; Cuq, J. L.; Lorient, D. Em Food Chemistry; Fennema, O. R., ed.; Marcel Dekker, Inc.: New York, 1985, p. 245-369. 